Research Paper

\title{
Colonization of oropharynx and lower respiratory tract in critical patients: Risk of ventilator-associated pneumonia
}

\author{
Ivany Machado de Carvalho Baptista ${ }^{\mathrm{a}}$, Frederico Canato Martinho ${ }^{\mathrm{a}}$, \\ Gustavo Giacomelli Nascimento ${ }^{\mathrm{b}}$, Carlos Eduardo da Rocha Santos ${ }^{\mathrm{a}}$, Renata Falchete do Prado ${ }^{\mathrm{a}, *}$, \\ Marcia Carneiro Valera ${ }^{\mathrm{a}}$
}

a Institute of Science and Technology, UNESP - Univ Estadual Paulista, Av. Eng. Francisco José Longo, 777, Jd São Dimas, São José dos Campos, São Paulo, Brazil

b Section of Periodontology, Department of Dentistry and Oral Health, Aarhus University, Aarhus, Denmark

\section{A R T I C L E I N F O}

\section{Keywords:}

Ventilator-associated pneumonia

Intensive care unit

Oral cavity

Bacteria

\begin{abstract}
A B S T R A C T
Objective: To investigate the microbial diversity existing in oral cavity and respiratory tract samples (from minibronchoalveolar lavage (BAL), endotracheal aspirate, and orotracheal tube) of patients on mechanical ventilation by using the checkerboard DNA-DNA hybridisation. Also, the study aimed to evaluate whether the microbial profile in the oral cavity is found in respiratory tract samples, at different periods of mechanical ventilation time $(12 \mathrm{~h}, 48 \mathrm{~h}, 96 \mathrm{~h})$ in attempt to identification of relationship between VAP (ventilator-associated pneumonia) and bacterial species studied. The last objective was to analyses correlation between blood cultures and VAP. Design: The samples were collected from ten patients in intensive care unit with medical prescription of orotracheal intubation and mechanical ventilation. Clinical data were tabulated and blood cultures were performed according medical indication. For checkerboard samples collection, chosen sites were the dorsal side of the tongue and gingival sulcus at $12 \mathrm{~h}, 48 \mathrm{~h}, 96 \mathrm{~h}, \mathrm{BAL}$, at $12 \mathrm{~h}$, endotracheal aspirate at 48 and $96 \mathrm{~h}$, and orotracheal tube at extubation time, when feasible.

Results: It was possible to identify the presence of bacterial species in mouth and in the BAL/endotracheal aspirate. The data demonstrated an increase in the quantity of bacterial associated with prolonged use of mechanical ventilation (48 and $96 \mathrm{~h}$ ).

Conclusions: Bacterial species may migrate rapidly from mouth and upper airways during orotracheal intubation which contributes to the pathogenesis of VAP. There were associations between VAP and Enterococcus faecalis, Fusobacterium periodonticum, Gemella morbillorum, Neisseria mucosa, Propionibacterium acnes, Prevotella melaninogenica, Streptococcus oralis, Streptococcus sanguinis, Treponema denticola, Treponema socransckii, and Veillonella parvula.
\end{abstract}

\section{Introduction}

Pneumonia is the second most common hospital infection and the main cause of mortality among the hospital-acquired infections. Aspiration of microorganisms from the oropharynx into the lower respiratory tract, followed by bacterial proliferation and invasion of parenchyma, is the most important way by which ventilator-associated pneumonia (VAP) develops. Also, it may be occurs due to inhalation of contaminated aerosols or, less frequently, by haematogenic dissemination from a remote focus (Cavalcanti, Valencia, \& Torres, 2005).

The ventilator-associated pneumonia (VAP) is characterised by the development of lung infection after $48 \mathrm{~h}$ of orotracheal intubation (OTI) and within $48 \mathrm{~h}$ of invasive mechanical ventilation (IMV) following extubation. Critical patients in intensive care unit (ICU) who are submitted to OTI and IMV present a VAP incidence above $78 \%$, with mortality rate ranging from $24 \%$ to $76 \%$ depending on the population studied and technique used for pneumonia diagnosis (Bahrani-Mougeot et al., 2007).

The aetiology of VAP is variable and depends on time elapsed after initiation of mechanical ventilation, hospitalisation length, population, and hospital proceedings. Bahrani-Mougeot et al. (2007) analysed microorganisms from oral cavity and BAL by using the method of molecular cloning and sequencing to identify the most common species, namely: Staphylococcus aureus, Streptococcus pneumoniae and Haemophilus influenzae, which are predominant in the initial stage of VAP. Gram-negative aerobic bacteria, including species of enterobacteria

\footnotetext{
* Corresponding author.

E-mail addresses: renatafalchete@hotmail.com, renata.prado@ict.unesp.br (R.F.d. Prado).
} 
Table 1

Strains used for the development of bacterial DNA probes.

\begin{tabular}{|c|c|c|c|}
\hline Species & Strain ATCC & Species & Strain ATCC \\
\hline Actinomyces gerecseriae & 238060 & Leptotrichia bucallis & 14201 \\
\hline Actinomyces israelii & 12102 & Neisseria mucosa & 19696 \\
\hline Actinomyces oris & 43146 & Parvimonas micra & 33270 \\
\hline Actinomyces odontolyticus & 17929 & Porphyromonas gingivalis & 33277 \\
\hline Aggregatibacter actinomycetemcomitans & $43718+29523$ & Prevotella intermedia & 25611 \\
\hline Campylobacter gracilis & 33236 & Prevotella melaninogenica & 25845 \\
\hline Campylobacter rectus & 33238 & Prevotella nigrescens & 33563 \\
\hline Campylobacter showae & 51146 & Propionibacterium acnes & $11827+11828$ \\
\hline Capnocytophaga gingivalis & 33624 & Selenomonas noxia & 43541 \\
\hline Capnocytophaga ochracea & 33596 & Streptococcus anginosus & 33397 \\
\hline Capnocytophaga sputigena & 33612 & Streptococcus constellatus & 27823 \\
\hline Eikenella corrodens & 23834 & Streptococcus gordonii & 10558 \\
\hline Enterococcus faecalis & 29212 & Streptococcus intermedius & 27335 \\
\hline Eubacterium nodatum & 33099 & Streptococcus mitis & 49456 \\
\hline Eubacterium saburreum & 33271 & Streptococcus oralis & 35037 \\
\hline Fusobacterium nucleatum spp. Polymorphum & 10953 & Streptococcus sanguinis & 10556 \\
\hline Fusobacterium nucleatum ssp. Nucleatum & 25586 & Tanerella forsythia & 43037 \\
\hline Fusobacterium nucleatum ssp. Vicentii & 49256 & Treponema denticola & B1 \\
\hline Fusobacterium periodonticum & 33693 & Treponema socransckii & S1 \\
\hline Gemella morbillorum & 27824 & Veillonella parvula & 10790 \\
\hline
\end{tabular}

(Enterobacteriaceae family), are reported in both initial and advanced stages of the disease. Pseudomonas aeruginosa and species belonging to the Acinobacter and Enterobacter classes are more predominant in the more advanced stages only. $H$. influenzae and $S$. pneumoniae are more predominant in polytraumatized patients during the post-operatory period (Bahrani-Mougeot et al., 2007).

In a literature review, Paju and Scannapieco (2007) found an important role played by oral bacteria in the respiratory infections, suggesting that pathogens existing in the oral cavity such as Streptococcus pneumonia, Haemophilus influenza and Mycoplasma pneumoniae colonise the lower respiratory tract (Paju \& Scannapieco, 2007).

Beraldo and Andrade (2008) reported that oral microbiota undergoes changes following intubation as there is an increase in microorganisms and formation of biofilm after $48 \mathrm{~h}$ (Beraldo \& Andrade, 2008). Gram-negative bacteria are frequently isolated from both dental biofilm and pulmonary secretion, with the former consisting of multiple bacteria such as Pseudomonas aeruginosa, Proteus spp., Acinetobacter spp. and Staphylococcus aureus (Bassin \& Niederman, 1995).

One of the methods used for exploring the microbial diversity is the checkerboard DNA-DNA hybridization, which allows the investigation of multiple bacteria species by using a large number of samples containing microorganisms. It is a rapid and relatively viable technique in terms of economic perspective (Socransky et al., 2004).

Therefore, the present study aimed identify the microbial diversity existing in the oral cavity and their presence in both bronchoalveolar lavage (BAL) and endotracheal aspirate, including the microbial profile in ICU patients on IMV at different periods of OTI and the association between VAP and bacterial load obtained by DNA probes of the species studied.

\section{Materials and methods}

\subsection{Study design and participants}

This research was approved by the Institutional Ethics Committee (protocol \# 283.047). For this clinical trial, samples were collected from ten patients recruited from the Intensive Care Unit at the POLICLIN hospital, São José dos Campos, São Paulo, Brazil. The laboratorial study was conducted at the Institute of Science and Technology, São Paulo State University, UNESP.

Prior to obtain the initial sample, all the patients were evaluated to collect clinical data: personal information, general health conditions and oral cavity situation of all individuals were recorded. Before the inclusion and exclusion criteria been applied, ICU responsible doctor evaluated each case and had selected a list of patient for this research. Ten critical ICU patients who were on invasive mechanical ventilation through orotracheal tube were included in the study, according inclusion (orotracheal intubation, presence of at least one tooth, and no severe or terminal lung disease) and exclusion criteria (Terminal and severe conditions, total teeth absence, acute oral infection, BAL with purulent aspect, and informed consent form not signed by the patient responsible relative or the patient).

Initial samples were obtained from bronchoalveolar lavage, two places in mouth: gingival sulcus (collected with paper cone), and dorsal side of the tongue (collected with swab), $12 \mathrm{~h}$ after the orotracheal intubation. After $48 \mathrm{~h}$ and $96 \mathrm{~h}$, samples were collected from endotracheal aspirate, gingival sulcus, and dorsal side of the tongue. Finally, the last samples were gathered from the inner part of the orotracheal tube, with swab, after extubation.

The collection of endotracheal aspirate was performed according to standard procedure, using a 12 siliconized polyvinyl chloride (PVC) tracheal aspiration probe and the aspirated secretion was put into a sterile polypropylene collector tube (Eppendorf).

BAL was proceeded using telescoping catheters manually guided. The catheter were placed, locked and $20 \mathrm{ml}$ of saline were instilled. Sample was obtained aspirating with vacuum to $40-60 \mathrm{~mm} \mathrm{Hg}$ and immediately placed in sterile tube.

All the samples obtained were transferred to VMGAIII medium at temperature of up to $2{ }^{\circ} \mathrm{C}$ and kept at $-20{ }^{\circ} \mathrm{C}$ for maintenance of their viability for further laboratorial processing.

For DNA Checkerboard analysis, samples and DNA standards representing $10^{5}$ and $10^{6}$ cells for target species were fixed on a membrane in thin lanes, then simultaneously cross-hybridized with 40 labelled, whole genome probes.

DNA from selected bacteria for probes, was isolated and purified as described previously (Smith, Socransky, \& Smith, 1989). The genomic probes were prepared for each one of the 40 species (Table 1) by conjugating $1 \mathrm{mg}$ of bacterial DNA with digoxigenin, by the random primer labelling kit Digoxigenin (Roche Diagnostics', Indianapolis, IN, USA) according to the method described previously (Feinberg \& Vogelstein, 1983).

After hybridisation with such probes, the membranes were removed from the Miniblotter 45 apparatus treated according as previously described (Smith et al., 1989; Socransky et al., 2004) and placed in a radiographic film cassette (Kodak ${ }^{\circ} \mathrm{X}$-OMAT, Kodak Brasileira Com. e Ind. Ltda, São José dos Campos, SP, Brazil) for approximately 40 min 
and the films were revealed (Socransky et al., 2004).

The signal produced by a determined probe of the samples was compared to that produced by the same probe of both controls containing $10^{5}$ and $10^{6}$ cell. The intensity of hybridisation was divided into six different classes in relation to the amount scores observed: $0=$ not detected; $1=<10^{5}$ cells, $2=10^{5}$ cells, $3=$ between $10^{5}$ and $10^{6}$ cells; $4=$ approximately $10^{6}$ cells, and $5=>10^{6}$ cells $/ \mathrm{mL}$.

Samples for blood cultures were obtained based on the indication and medical prescription. Two sample collections were made $(20 \mathrm{ml})$, obtained in two different locations (e.g. left upper member and right upper member). In the case of microorganisms growth, colony-forming units (CFU)/mL, antibiograms and Gram Stain were performed.

\subsection{Statistical analysis}

Data were analysed by using the STATA software, version 12.0 (StataCorp., College Station, Texas, USA). Kruskal-Wallis test was performed to evaluate the association between VAP with the DNA of the bacterial species. Descriptive comparisons were based on bacterial load between different sites and different time of collection. Additionally, the Fisher exact test was conducted to test the association between clinical signs and positive hemoculture. In order to determine possible associated bacterial species with presence of positive blood culture, the Kruskal-Wallis test was performed. For all the tests above, the significance level was set at 5\% ( $\mathrm{p}<0.05)$.

\section{Results}

Among the patients, six were male and four female aging from 35 to 85 years (mean 63 year old). During search, eight patients died. Among then, five reached PAV diagnosis criteria, confirmed by auscultation and $\mathrm{X}$ ray images (Table 2 ).

All of them presented poor oral hygiene in the clinical examination, and 9 of them contained supragingival calculus.

The results of Checkerboard showed that all bacteria selected were found in, at least, one of the samples of the evaluated sites. Bacteria load ranged from 0 to 3 (up to $10^{6}$ cells).

Evaluating the association between VAP and bacterial species; patients presenting VAP were grouped and compared to that patients not presenting VAP. A median of microbial load (each specie) collected from each site were compared between these two groups and the data evaluated using Kruskal Wallis test ( $p>0.05$ ) (Table 3). Observing the table, among significant statistical results, only three species related to VAP were detected in sample collected outside the mouth: $P$. melaninogenica (in BAL), $P$. acnes (in endotracheal aspirate) and $S$. sanguinis (in endotracheal aspirate). For all others significant results, samples were collect in lingual mucosa or gingival sulcus. After $12 \mathrm{~h}$, S. oralis, $N$. mucosa and T. socranskii were related to pneumonia. After $48 \mathrm{~h}, N$. mucosa, S. oralis, and T. denticola were related to pneumonia. After $96 \mathrm{~h}$, E. faecalis, F. periodonticum, G. morbillorum and V. parvula were related

Table 2

Clinical data of each patient.

\begin{tabular}{llllllll}
\hline Sex & Age & $\begin{array}{l}\text { Oral } \\
\text { Hygiene }\end{array}$ & $\begin{array}{l}\text { Visible } \\
\text { Tartar }\end{array}$ & $\begin{array}{l}\text { Teeth } \\
\text { Number }\end{array}$ & Blood Culture & Fever & VAP \\
\hline M & 71 & poor & $\mathrm{X}$ & 5 & - & - & - \\
M & 48 & poor & $\mathrm{X}$ & 20 & $\begin{array}{l}\text { S. epidermidis/S. } \\
\text { aureus }\end{array}$ & $\mathrm{X}$ & - \\
& & & & & & \\
F & 78 & poor & $\mathrm{X}$ & 6 & S. aureus & $\mathrm{X}$ & $\mathrm{X}$ \\
M & 35 & poor & - & 32 & - & - & - \\
F & 70 & poor & $\mathrm{X}$ & 4 & S. aureus & $\mathrm{X}$ & - \\
M & 59 & poor & $\mathrm{X}$ & 16 & - & $\mathrm{X}$ & $\mathrm{X}$ \\
$\mathrm{F}$ & 56 & poor & $\mathrm{X}$ & 8 & - & $\mathrm{X}$ & $\mathrm{X}$ \\
M & 57 & poor & $\mathrm{X}$ & 3 & - & $\mathrm{X}$ & $\mathrm{X}$ \\
$\mathrm{F}$ & 70 & poor & $\mathrm{X}$ & 12 & S. aureus & $\mathrm{X}$ & $\mathrm{X}$ \\
M & 85 & poor & $\mathrm{X}$ & 2 & - & - & - \\
\hline
\end{tabular}

Table 3

Statistical significant association between cases of VAP and Checkerboard data according to bacterial species (significant level 5\%).

\begin{tabular}{llll}
\hline Bacteria & Collection sites & Time & P value \\
\hline E. faecalis & lingual mucosa & $96 \mathrm{~h}$ & $\mathrm{p}=0.041$ \\
F. periodonticum & lingual mucosa & $96 \mathrm{~h}$ & $\mathrm{p}=0.044$ \\
G. morbillorum & lingual mucosa & $96 \mathrm{~h}$ & $\mathrm{p}=0.047$ \\
N. mucosa & lingual mucosa & $12 \mathrm{~h}$ & $\mathrm{p}=0.016$ \\
N. mucosa & lingual mucosa & $48 \mathrm{~h}$ & $\mathrm{p}=0.040$ \\
P. acnes & endotracheal aspirate & $48 \mathrm{~h}$ & $\mathrm{p}=0.039$ \\
P. melaninogenica & BAL & $12 \mathrm{~h}$ & $\mathrm{p}=0.049$ \\
S. Oralis & gingival sulcus & $12 \mathrm{~h}$ & $\mathrm{p}=0.049$ \\
S. Oralis & Lingual mucosa & $48 \mathrm{~h}$ & $\mathrm{p}=0.047$ \\
S. sanguinis & Endotracheal aspirate & $48 \mathrm{~h}$ & $\mathrm{p}=0.048$ \\
T. denticola & lingual mucosa & $48 \mathrm{~h}$ & $\mathrm{p}=0.046$ \\
T. socranskii & gingival sulcus & $12 \mathrm{~h}$ & $\mathrm{p}=0.045$ \\
V. parvula & gingival sulcus & $96 \mathrm{~h}$ & $\mathrm{p}=0.039$ \\
\hline
\end{tabular}

to pneumonia.

To analyze the frequency of detection and concentration of DNA of the bacteria species, the following sites were studied: oral cavity (dorsal site of tongue and gingival sulcus) after 12,48 , and $96 \mathrm{~h}$; BAL after $12 \mathrm{~h}$; endotracheal aspirate after 48 and $96 \mathrm{~h}$, and endotracheal tube after orotracheal extubation, when feasible. (see Fig. 1A-C). A mean DNA concentration (bacterial load) from each site, in each experimental period $(n=10)$, was obtained and used to analyse microbiota progression after mechanical ventilation started.

Fig. 1 presents the frequency of detection and bacterial load, according to the sample site: dorsal tongue mucosa (A), gingival sulcus (B) and BAL/endotracheal aspirate (C), at different times.

In the tongue, after $12 \mathrm{~h}$ of intubation, observing the blue line in Fig. 1A, the microorganisms that were found in greater amounts were $T$. socranskii, $F$. nucleatum and the A. israelli. After 48, the red line demonstrated that the $P$. micra and A. oris had statistically significant increase and were the most prevalent. At this period, A. odontolyticus and $P$. nigrescens increased significantly. At $96 \mathrm{~h}$, T. socranskii, F. nucleatum, E. nodatum and A. israelli, according yellow line in Fig. 1A, presented the highest bacterial load. Statistical significant increase was demonstrated in bacterial load of $E$. nodatum, $L$. bucallis, $P$. nigrescens, $S$. noxia and T. socranskii when comparing 48 and $96 \mathrm{~h}$ after intubation. Instead, A. odontolyticus, A. oris, P. micra, S. anginosus, S. gordonii, and V. parvula presented significant reduction from $48 \mathrm{~h}$ to $96 \mathrm{~h}$.

In gingival sulcus, the bacterial load at $12 \mathrm{~h}$ after intubation, according blue line of Fig. 1B, higher values were observed in T. socranskii, F. nucleatum, and A. israelli. After $48 \mathrm{~h}$, red line in Fig. 1B demonstrated that A. odontolyticus, C. gingivalis, E. saburreum, F. polymorphum, $F$. vicentii, F. nucleatum, L. bucallis, $P$. gingivalis, $S$ constellatus, $T$. socranskii and $V$. parvulla reduced significantly. Observing yellow line in Fig. 1B and applying statistical test, E. saburreum, F. nucleatum, $F$. vicentii, G. morbillorum, and $P$. gingivalis presented higher values of bacterial load at $96 \mathrm{~h}$, when comparing with $48 \mathrm{~h}$ post intubation.

In BAL at $12 \mathrm{~h}$ after intubation, illustrated by blue line in Fig. 1C, higher values were demonstrated in the following bacterial species: $P$. micra, T. socranskii, and F. nucleatum. Red line in Fig. 1C represents endotracheal aspirate bacterial load at $48 \mathrm{~h}$ after intubation. Statistical test proved significant increase in S. sputigena, E. nodatum, F. nucleatum, N. mucosa, P. nigrescens, S. gordonii, S. constellatus, T. denticola, T. socranskii and $V$. parvula. Instead, significant reduction was demonstrated in A. odontolyticus, when comparing 12 and $48 \mathrm{~h}$. At $96 \mathrm{~h}$ after intubation, yellow line in Fig. 1C and statistical results demonstrated that C. showae, C. sputigena, and L. bucallis presented higher bacterial load, when comparing with period of $48 \mathrm{~h}$.

Blood culture proved $S$. epidermidis and/or $S$. aureous growing in five patients. Fisheŕs Exact test proved significant association between fever and blood culture results. Instead, no correlation between VAP patients and positive blood culture patients was significant. All five positive 

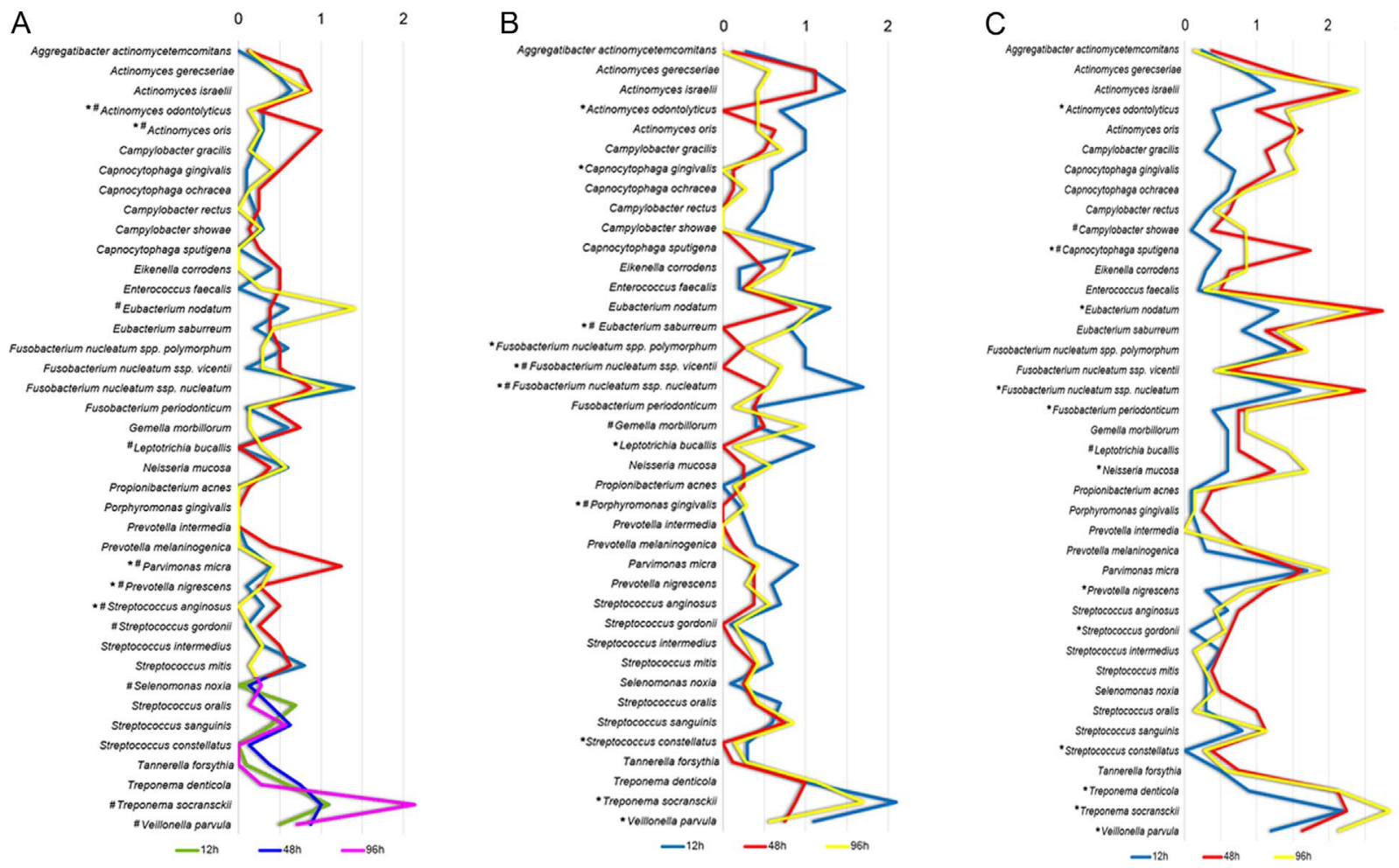

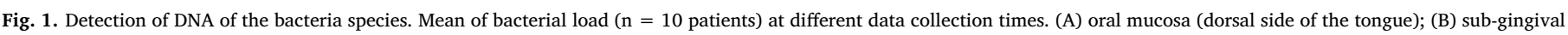
space; (C) BAL (12 h)/endotracheal aspirate (48 and $96 \mathrm{~h}$ ).

*statistical difference for 12-h and 48-h periods of intubation; \# statistical difference for the 48-h and 96-h periods of intubation, $\mathrm{p}<0.05$.

$0=$ not detected; $1=<10^{5}$ cells, $2=10^{5}$ cells. (For interpretation of the references to colour in the text, the reader is referred to the web version of this article.)

blood culture patients presented fever; two more patients that presented fever had negative blood culture results as observed in Table 2.

The Kruskal-Wallis test ( $\mathrm{p}<0.05$ ) was used to assess the association between blood culture results and bacteria species; patients presenting positive blood culture were grouped and compared to that patients not presenting bacterial growing. Median of microbial load (each specie) collected from each site were compared between these two groups. Only data presenting statistical significance are demonstrated in Table 4. Significantly higher microbial load of $F$. nucleatum, S. mitis, $T$. socransky and $V$. parvula, collected from mouth and BAL were found in patients with positive blood culture.

In extubation $T$. socranskii, $E$. nodatum and $P$. micra were the most prevalent bacteria in samples.

\section{Discussion}

The checkerboard DNA-DNA hybridisation technique was first described in 1994 by Socransky et al., who used specific probes of 40 bacteria species to show that the sub-gingival plaque contains different bacterial complexes, including their association with the severity of periodontal disease.

The oral microbiota may be one of the causes of pulmonary

Table 4

Statistical significant association between cases of positive blood culture and Checkerboard data according to bacterial species (significant level 5\%).

\begin{tabular}{llll}
\hline Bacteria & Collection sites & Time & P value \\
\hline F nucleatum & lingual mucosa & $12 \mathrm{~h}$ & $\mathrm{p}=0.046$ \\
S mitis & BAL & $12 \mathrm{~h}$ & $\mathrm{p}=0.038$ \\
$T$ socranskii & lingual mucosa & $12 \mathrm{~h}$ & $\mathrm{p}=0.043$ \\
$T$ socranskii & gingival sulcus & $12 \mathrm{~h}$ & $\mathrm{p}=0.037$ \\
T socranskii & BAL & $12 \mathrm{~h}$ & $\mathrm{p}=0.028$ \\
V parvula & lingual mucosa & $12 \mathrm{~h}$ & $\mathrm{p}=0.039$ \\
\hline
\end{tabular}

complications patient in the ICU, since, in the mechanical ventilation procedures microorganisms can be aspired to the lungs, facilitating the installation of the ventilator associated pneumonia.

According to Rouby et al. (1992), the "gold standard" for diagnosis of pneumonia would be histological, however, this is not feasible nor desirable in critics patients. For Wood et al. (2005), the clinical diagnosis is important since only $39 \%$ of their sample of 299 patients suspected to have VAP showed positive BAL culture (Wood et al., 2005). Despite a definitive diagnosis of VAP be performed with BAL culture, empirically antibiotic therapy for VAP may be early initiated and require several changes depending on the microorganism susceptibility and disease evolution. The present research showed that $50 \%$ of sample had VAP diagnosis. These patients presented the criteria described in literature, been VAP defined when the chest radiograph shows new or progressive infiltrate in association with at least two or three criteria: fever, purulent pulmonary secretion, and leukocytosis (Niederman, 2010).

In our study, it was observed that clinical evolution and complementary exams (e.g. leukograms and chest radiography) in association with signs and symptoms as well as physical exam (especially pulmonary auscultation) were the parameters for diagnosis of VAP. Given the clinical presentation, it is a reasonable assumption that, in a febrile patient with chest radiographic changes, the recovered predominant bacteria in a BAL sample would be responsible for the VAP. Clinical management and antibacterial therapy are based on this assumption, which is well supported by clinical evidence (BahraniMougeot et al., 2007).

The difficulty in diagnosing VAP is due to some factors such as possibility of other causes of systemic inflammatory response, previous use of antibiotics, and lack of diagnostic method for VAP (Woske, Roding, Schulz, \& Lode, 2001). The mini-BAL is an efficient method with better cost-benefit results when performed by trained physical therapists and nurses. In present study, mini-BAL was carefully 
proceeded to also be used as important sample collection method for Checkerboard molecular test. In a study carried out at the Madison University Hospital, Wisconsin, USA, 399 bronchoscope procedures (BAL) were performed between 1st July 2002 and 31st June 2007 for acquisition of specimens from the right and left lungs, totalizing 789 specimens for culture. This resulted in 405 bacteria isolated from the BAL samples. The most frequently isolated bacteria were $S$. aureus (27.6\%), methicillin-resistant $S$. aureus (6.2\%), P. aeruginosa (16.8\%), and $H$. Influenzae (15.5\%) (Zaccard, Schell, \& Spiegel, 2009).

However, in the present study, we evaluated if mouth bacteria may be associated with VAP. Safdar, Crnich, and Maki (2005) reported that the physiopathology of VAP is more likely to occur due to oropharyngeal colonisation (Safdar et al., 2005).

In our study, using DNA specific probes, it was possible to identify oral, tracheal and lungs microbiota. After analyse checkerboard DNADNA hybridisation data, it was demonstrated the association between VAP and bacterial, with statistical significance, for the following species: E. faecalis, F. periodonticum, G. morbillorum, N. mucosa, P. acnes, $P$. melaninogenica, S. oralis, S. sanguinis, T. denticola, T. socransckii, and V. parvula. Several factors such as temperature, $\mathrm{pH}$, salivary flow, nutrients, adherence and agglutination affect the growth of microorganisms within the oral cavity (Morais et al., 2006; Rosenthal et al., 2006), mainly in critical patients on ICT since dental biofilm increases over time in these patients (Fourrier, Duvivier, Boutigny, RousselDelvallez, \& Chopin, 1998).

In our study, the oral hygiene was evaluated based on the presence of visible calculus, Coated tongue, intense drooling or xerostomia, lesions in mucosa, tongue and lips, bleeding, and dentition. It was found that the longer the time of OTI, the higher the concentration of bacterial load for the species identified at different sites, with gingival sulcus and BAL/endotracheal aspirate exhibiting the highest concentrations. Supragingival calculus were presence in most of patient. Any patient presented good hygiene in our samples, been highly suggestive of association between oral hygiene and VAP.

When analysed separately, the collection sites showed higher concentrations of bacterial load in relation to the time of OTI. Oral hygiene maintenance as well as effectiveness and adaptation of oral hygiene protocols to be followed by all practitioners on a proper and standardised basis will promote satisfactory results and decrease the bacterial load of the oral microbiota (Abidia, 2007; Bahrani-Mougeot et al., 2007; Brennan et al., 2004).

The critical patient's oral microbiota changes over time and the orotracheal tube becomes predominantly colonised by Gram-negative bacteria, and the use of $0.12 \%$ chlorhexidine was shown to have a beneficial effect regarding the prevention against VAP (Amaral, Cortes Ade, \& Pires, 2009; Heo, Haase, Lesse, Gill, \& Scannapieco, 2008; Koeman et al., 2006; Munro \& Grap, 2004).

According Fig. 1, after OTI, a complex microbiota was presented in BAL and tracheal aspiration sample. A descending way is coursed by the bacterial, and aspiration results in a more complex aetiology to VAP. The analysis of the tube, after extubation supports this descending pathway, showing bacterial profile similar to the endotracheal aspirate.

Probably VAP had been caused by a group of species, besides the common described bacteria such as $S$. aureus, $S$. pneumoniae and $H$. influenzae. It is important to keep in mind, that classical aetiological descriptions were stated based on culture results. Culture-based methods are not sufficient for accurate identification of the bacterial species associated with VAP (Bahrani-Mougeot et al., 2007) and to determine causal agents of the diseases. Blood sample were accessed and the frequency of positive cultures in present research was $50 \%$. $S$. epidermidis and/or $S$. aureous growth in their blood culture. Usually literature varies between $8-20 \%$. Some studies point to the fact that bacteraemia in critically ill patients, is not always associated with VAP and $50 \%$ of patients with positive blood cultures may have additional infections (Luna et al., 1999).

Among our patients, $80 \%$ dead during research. Pneumonia together with influenza is a top ten cause of death in the world, and in elderly nursing home residents the leading cause of death. Mean age demonstrated an elderly sample. In intensive care units pneumonia is the most common infection in hospital setting (Paju \& Scannapieco, 2007). In this research, the most frequent death cause was cardiogenic and septicaemia complications.

The interventions performed by nurses for maintenance of the oral hygiene are varied, in general with each patient receiving individual care during the mechanical interventions, such as tooth-brushing and rinsing of the oral cavity as well as pharmacological interventions by means of application of antimicrobial agents. All these can be paramount in the prevention of VAP (Abidia, 2007; Sona et al., 2009).

In addition to the tooth-brushing, other preventive measures, such as head-of-bed elevation at $30^{\circ}$ and daily gauging of cut-off pressure of the orotracheal tube, can reduce the incidence of infections. Measures like oral aspiration, hydration of mucosa and lips can also decrease the risk factors for VAP (Chlebicki \& Safdar, 2007; Silvestri et al., 2009; Sona et al., 2009).

In fact, VAP is directly related to a poor oral hygiene. This study on the identification of oral mucosa present in BAL/endotracheal aspirate is of crucial importance and can guide therapeutic protocols aimed at fighting these infections efficiently. We hope that integration of intensive medicine, dentistry and nursing will be stimulated by the results of the present research with the assignment of a surgeon-dentist to the hospital, especially in the intensive therapy units. The present research provided important information concerning the aetiology of VAP in this patient population. To understanding of the sequential development of VAP and the association with the oral bacteria is critical to decide the effective interventions.

\section{Conclusion}

It was possible to study the microbial diversity existing in the oral cavity (dorsal site of tongue mucosa, gingival sulcus) and identify the presence of bacteria in the BAL of ICU patients on mechanical ventilation by using the checkerboard DNA-DNA hybridisation technique, with higher DNA loads of some bacteria species being found in both tongue mucosa and gingival sulcus.

The microbial profile present in the oral cavity was identified in the BAL at different periods of invasive mechanical ventilation $(12 \mathrm{~h}, 48 \mathrm{~h}$, and $96 \mathrm{~h}$ ), including in the orotracheal tube after extubation. It was found that the longer the time of intubation, the higher the bacterial load identified. Also, associations between VAP and the following bacterial species studied were found, namely, E. faecalis, F. periodonticum, G. morbillorum, N. mucosa, P. bacterium, P. melaninogenica, S. oralis, S. sanguinis, T. denticola, T. socransckii, and V. parvula.

The positive blood culture showed association with fever and with the bacteria F. nucleatum, S. mitis, T. socranski, and V. parvula.

\section{Conflict of interests}

The authors report no conflict of interest relating to this study.

\section{Funding}

This study was supported by Univ Estadual Paulista-UNESP. Coordenação de Aperfeiçoamento de Pessoal de Nível Superior - CAPES and Fundação de Amparo à Pesquisa do Estado de São Paulo - FAPESP grant: 2014/25789-9.

\section{Ethical approval}

Ethical approval was previously obtained from the Institutional Review Board of the State University of São Paulo-UNESP, and received the reference number 283.047. 


\section{References}

Abidia, R. F. (2007). Oral care in the intensive care unit: A review. Journal of Contemporary Dental Practice, 8(1), 76-82.

Amaral, S. M., Cortes Ade, Q., \& Pires, F. R. (2009). Nosocomial pneumonia: Importance of the oral environment. Journal Brasileiro de Pneumologia, 35(11), 1116-1124.

Bahrani-Mougeot, F. K., Paster, B. J., Coleman, S., Barbuto, S., Brennan, M. T., Noll, J., et al. (2007). Molecular analysis of oral and respiratory bacterial species associated with ventilator-associated pneumonia. Journal of Clinical Microbiology, 45(5), 1588-1593.

Bassin, A. S., \& Niederman, M. S. (1995). New approaches to prevention and treatment of nosocomial pneumonia. Seminars in Thoracic and Cardiovascular Surgery, 7(2), 70-77.

Beraldo, C. C., \& Andrade, D. (2008). Oral hygiene with chlorhexidine in preventing pneumonia associated with mechanical ventilation. Journal Brasileiro de Pneumologia, 34(9), 707-714.

Brennan, M. T., Bahrani-Mougeot, F., Fox, P. C., Kennedy, T. P., Hopkins, S., Boucher, R. C., et al. (2004). The role of oral microbial colonization in ventilator-associated pneumonia. Oral Surgery, Oral Medicine, Oral Pathology, Oral Radiology and Endodontics, 98(6), 665-672.

Cavalcanti, M., Valencia, M., \& Torres, A. (2005). Respiratory nosocomial infections in the medical intensive care unit. Microbes and Infection, 7(2), 292-301.

Chlebicki, M. P., \& Safdar, N. (2007). Topical chlorhexidine for prevention of ventilatorassociated pneumonia: A meta-analysis. Critical Care Medicine, 35(2), 595-602.

Feinberg, A. P., \& Vogelstein, B. (1983). A technique for radiolabeling DNA restriction endonuclease fragments to high specific activity. Analytical Biochemistry, 132(1), $6-13$.

Fourrier, F., Duvivier, B., Boutigny, H., Roussel-Delvallez, M., \& Chopin, C. (1998). Colonization of dental plaque: A source of nosocomial infections in intensive care unit patients. Critical Care Medicine, 26(2), 301-308.

Heo, S. M., Haase, E. M., Lesse, A. J., Gill, S. R., \& Scannapieco, F. A. (2008). Genetic relationships between respiratory pathogens isolated from dental plaque and bronchoalveolar lavage fluid from patients in the intensive care unit undergoing mechanical ventilation. Clinical Infectious Diseases, 47(12), 1562-1570.

Koeman, M., van der Ven, A. J., Hak, E., Joore, H. C., Kaasjager, K., de Smet, A. G., et al. (2006). Oral decontamination with chlorhexidine reduces the incidence of ventilatorassociated pneumonia. American Journal of Respiratory and Critical Care Medicine, 173(12), 1348-1355.

Luna, C. M., Videla, A., Mattera, J., Vay, C., Famiglietti, A., Vujacich, P., et al. (1999). Blood cultures have limited value in predicting severity of illness and as a diagnostic tool in ventilator-associated pneumonia? Chest, 116(4), 1075-1084.

Morais, T. M. N., Silva, S., Avi, A. L. R. O., Souza, P. H. R., Knobel, E., \& Camargo, L. F. A. (2006). A importância da atuação odontológica em pacientes internados em unidade de terapia intensiva: Revisão. Revista Brasileira de Terapia Intensiva, 18, 412-417.

Munro, C. L., \& Grap, M. J. (2004). Oral health and care in the intensive care unit: State of the science. American Journal of Critical Care, 13(1), 25-33.

Niederman, M. S. (2010). The argument against using quantitative cultures in clinical trials and for the management of ventilator-associated pneumonia. Clinical Infectious Diseases, 51(Suppl. 1), S93-99.

Paju, S., \& Scannapieco, F. A. (2007). Oral biofilms, periodontitis, and pulmonary infections. Oral Diseases, 13(6), 508-512.

Rosenthal, V. D., Maki, D. G., Salomao, R., Moreno, C. A., Mehta, Y., Higuera, F., et al. (2006). Device-associated nosocomial infections in 55 intensive care units of 8 developing countries. Annals of Internal Medicine, 145(8), 582-591.

Rouby, J. J., Martin De Lassale, E., Poete, P., Nicolas, M. H., Bodin, L., Jarlier, V., et al. (1992). Nosocomial bronchopneumonia in the critically ill. Histologic and bacteriologic aspects. American Review of Respiratory Disease, 146(4), 1059-1066.

Safdar, N., Crnich, C. J., \& Maki, D. G. (2005). The pathogenesis of ventilator-associated pneumonia: Its relevance to developing effective strategies for prevention. Respiratory Care, 50(6), 725-739 discussion 739-741.

Silvestri, L., van Saene, H. K., Milanese, M., Zei, E., \& Blazic, M. (2009). Prevention of ventilator-associated pneumonia by use of oral chlorhexidine. Infection Control and Hospital Epidemiology, 30(1), 101-102 author reply 102-103.

Smith, G. L., Socransky, S. S., \& Smith, C. M. (1989). Rapid method for the purification of DNA from subgingival microorganisms? Oral Microbiology and Immunology, 4(1), $47-51$

Socransky, S. S., Haffajee, A. D., Smith, C., Martin, L., Haffajee, J. A., Uzel, N. G., et al. (2004). Use of checkerboard DNA-DNA hybridization to study complex microbial ecosystems? Oral Microbiology and Immunology, 19(6), 352-362.

Sona, C. S., Zack, J. E., Schallom, M. E., McSweeney, M., McMullen, K., Thomas, J., et al. (2009). The impact of a simple, low-cost oral care protocol on ventilator-associated pneumonia rates in a surgical intensive care unit. Journal of Intensive Care Medicine, 24(1), 54-62.

Wood, G. C., Mueller, E. W., Croce, M. A., Boucher, B. A., Hanes, S. D., \& Fabian, T. C. (2005). Evaluation of a clinical pathway for ventilator-associated pneumonia: Changes in bacterial flora and the adequacy of empiric antibiotics over a three-year period. Surgical Infections (Larchmt), 6(2), 203-213.

Woske, H. J., Roding, T., Schulz, I., \& Lode, H. (2001). Ventilator-associated pneumonia in a surgical intensive care unit: Epidemiology, etiology and comparison of three bronchoscopic methods for microbiological specimen sampling. Critical Care, 5(3), 167-173.

Zaccard, C. R., Schell, R. F., \& Spiegel, C. A. (2009). Efficacy of bilateral bronchoalveolar lavage for diagnosis of ventilator-associated pneumonia. Journal of Clinical Microbiology, 47(9), 2918-2924. 